\title{
When Do Secondary Markets Harm Firms?
}

\author{
By Jiawei Chen, Susanna Esteban, and Matthew Shum*
}

\begin{abstract}
To investigate whether secondary markets aid or harm durable goods manufacturers, we build a dynamic model of durable goods oligopoly with transaction costs in the secondary market. Calibrating model parameters using data from the US automobile industry, we find the net effect of opening the secondary market is to decrease new car manufacturers' profits by 35 percent. Counterfactual scenarios in which the size of the used good stock decreases, such as when products become less durable, when the number of firms decreases, or when firms can commit to future production levels, increase the profitability of opening the secondary market. (JEL L13, L25, L62, L81)
\end{abstract}

In recent years, the rapid rise of Internet retailing has jump-started a multitude of markets for a wide spectrum of used goods: virtually everything is resold on the Internet, from animals to toys to books, plants, clothing, appliances; even automobiles and housing units. One market observer notes:

$[W]$ e are beginning to embrace the notion of temporary ownership. We will soon live in a world where the norm is to sell our designer shoes after wearing them twice, where Verizon will automatically send us the newest, best, most high tech mobile phone every six months, and where we'll lease our Rolex watches instead of buying them. The "informed consumer" will soon choose the brand of her next handbag based on how much it will likely fetch on eBay next year-which corresponds to how much it will really cost her to own it up until then. ${ }^{[}$

Has this dramatic expansion in secondary markets (or "temporary ownership," to use the colorful terminology above) helped or hurt new good producers? In determining the gains from secondary markets, we classify various countervailing

\footnotetext{
* Chen: University of California, Irvine, 3151 Social Science Plaza A, Irvine, CA 92697 (e-mail: jiaweic@uci. edu); Esteban: Universitat Autònoma de Barcelona and the Barcelona GSE, Building B, UAB, Bellaterra 08193, Spain (e-mail: susanna.esteban@gmail.com); Shum: California Institute of Technology, MC 228-77, 1200 East California Blvd., Pasadena, CA 91125 (e-mail: mshum@caltech.edu). Guofang Huang provided exceptional research assistance. We thank Eiichi Miyagawa, Ivan Png, and seminar participants at Arizona, Drexel, National University of Singapore, Stanford GSB, UC Davis, UCSD, Warwick, Wisconsin, IIOC 2007, Econometric Society NAWM 2008, the Industrial Economics workshop at Ente Einaudi (Rome, Italy) and EARIE 2009 for their helpful comments. We are grateful to two anonymous reviewers for their constructive suggestions. Esteban acknowledges the support of the European Commission (EFIGE 225343), of the Excellence Project of the Bank of Spain, of the Ministerio de Ciencia e Innovación (SEJ2007-65169) and of the Ministerio de Economía y Competitividad (ECO2011-28822). The authors declare that they have no relevant or material financial interests that relate to the research described in this paper. An earlier draft of the paper was entitled "How much competition is a secondary market?" We thank a referee for suggesting this change.

${ }^{\dagger}$ Go to http://dx.doi.org/10.1257/aer.103.7.2911 to visit the article page for additional materials and author disclosure statement(s).

${ }^{1}$ From Nissanoff (2006, pp.8-9).
} 
effects-a substitution, an allocative, and a time consistency effect. Whether secondary markets help or hurt producers is ultimately an empirical question, the answer to which depends on the market structure and the underlying market features, such as products' characteristics and consumers' preferences. Our main contribution in this paper is to build and calibrate a dynamic equilibrium model of a durable-goods industry to better understand the role that secondary markets play in oligopolistic industries with product depreciation and a heterogeneous consumer population.

In our analysis, transaction costs play a key role by letting us assess the effects that secondary markets play. By raising transaction costs, we close down secondary markets to hone in on the effects of durability itself on firms' behavior. In contrast, by decreasing transaction costs, we make transactions frictionless and can evaluate the effects of secondary markets on firms' profitability.

To our knowledge, our model is the first that analyzes a durable goods oligopoly model in a Markov-perfect equilibrium framework whilst allowing for realistic inertial behavior ("hysteresis") on the consumer side due to transaction costs. We calibrate our model's parameter values to match aggregate data from the US automobile industry in 1994-2003. To meet the challenge of computing the dynamic equilibrium oligopoly model, we use the MPEC approach (Mathematical Programming with Equilibrium Constraints), recently advocated by Su and Judd (2008).

Using the calibrated parameter values, we show that more active secondary markets lead to lower profits for producers, so that the negative effects of secondary markets appear to outweigh the benefits. We find that opening the secondary market from closed to frictionless lowers firms' profits (by 35 percent). Market scenarios in which the size of the used good stock decreases, such as when products become less durable, when the number of firms decreases, or when firms are able to commit to future production levels, increase the profitability of opening the secondary market. Moreover, changes in consumers' preferences leading to more persistence between current and past purchases also increase the profitability of opening the secondary market. We will expound in greater detail on these findings below.

The next section describes the various effects that opening secondary markets have on durable goods producers' profits and summarizes the relevant literature. Section II presents the model. Section III presents the calibration exercise and the model evaluation at the steady state. Section IV runs counterfactual experiments to address our core question, whether secondary markets aid or hurt durable goods manufacturers. Section V concludes.

\section{Opening Secondary Markets: A Taxonomy of Effects}

In durable goods markets, the purchase of a good entails the purchase of an asset. Whether secondary markets are open or closed affects the value of this asset and, in turn, the profits the firms earn.

Multiple interrelated effects are at play. First, there is a substitution effect. Even if the durable goods producer sells only a single product, it also places many products - all the used vintages - in the market. Since these products substitute with the new good, they cannibalize future demand in the primary and second markets, which affects current profits. The magnitude of this cannibalization effect on firm profits is largest when the secondary market works without frictions. In contrast, 
when the secondary market is closed, substitution possibilities with the used goods stock are much reduced; now, only consumers who own used goods can substitute between new and used goods, mitigating the negative substitution effect.

Second, there is an allocative effect. Because the price of a new good capitalizes its asset value, a durable goods manufacturer is, in a sense, a multi-product firm that earns revenue not only from selling the new good, but also (indirectly) from selling its older vintages. This multi-product firm gains if the efficiency of the allocation of vintages to heterogeneous consumers is improved. Secondary markets, by facilitating consumers' reoptimization, improve this allocation and therefore have a positive effect on firm profitability; they allocate the lower quality used vintages to the lower valuation consumers while allowing the firm to extract a larger surplus from selling new goods to the higher valuation consumers.

Lastly, there is a time consistency effect. Forward-looking consumers value the durable good depending on the expected future prices (and quantities). With and without secondary markets, a durable goods firm can raise this value, and thus its current earnings, if it can credibly commit to keeping future prices high by restricting output. Nonetheless, as pointed out by Coase (1972), without a commitment mechanism, such behavior is time inconsistent: once current profits are earned, the firm increases output, jeopardizing its overall profit. The effect of this increase in output is what determines the time consistency effect. More output implies more used goods stock, which exacerbates the negative substitution possibilities of secondary markets and modifies prices under indirect price discrimination. ${ }^{2}$

As the discussion above shows, secondary markets have multiple, interdependent, and oftentimes countervailing effects on firms' profitability. Our goal here is to highlight these effects using parameter values calibrated for the US automobile industry.

Related Literature.-This paper joins a long-standing literature, going back to the United States v. Alcoa (1945) monopolization case, in which a key issue was whether Alcoa faced substantial competition from the used (scrap) aluminum sector. ${ }^{3}$ Several papers have investigated whether firms would benefit from closing secondary markets, focusing on the allocative effect. Anderson and Ginsburgh (1994) and Hendel and Lizzeri (1999b) show that firms can benefit from indirect price discrimination when the secondary markets are active. Porter and Sattler (1999) also provide empirical evidence about the sorting role of secondary markets. In all these models, firms can fully commit to future prices (so there is no time consistency effect), and consumers are heterogeneous in the persistent component of their valuation of the good. Recently, Johnson (2010) extends this framework to allow consumers' preferences to change over time and finds that a two-period time-inconsistent monopolist may prefer to close down the secondary market. ${ }^{4}$

\footnotetext{
${ }^{2}$ See also Liang (1999). Indeed, Rust (1985), (1986) presents a model of a durable goods monopoly with commitment power in which the secondary market per se has no effect on either consumer or producer behavior.

${ }^{3}$ cf. Areeda and Kaplow (1988). Alcoa lost the case on appeal and, decades later, Suslow (1986) showed that Alcoa did indeed retain substantial market power despite the competition from the recyclable aluminum sector.

${ }^{4}$ In Johnson (2010), a monopolist may prefer to close down the secondary market because doing so induces consumers who obtain a low realization of their willingness to pay to keep the goods even though the firm would never sell to them. Such an effect is also present in our model.
} 
We build on the large empirical literature on dynamic demand in durable goods markets (see Erdem, Imai, and Keane 2003; Hendel and Nevo 2006; Melnikov 2000; Gowrisankaran and Rysman 2006; Gordon 2009; Hartmann 2006; Chevalier and Goolsbee 2009; Carranza 2007; Schiraldi 2006; and Copeland 2006).5 Following this literature, we assume that consumers' heterogeneous preferences have both a persistent component, as well as a time-varying component which causes consumers to reoptimize their product choices due to stochastic changes in their needs. As we see below, the desirability of secondary markets for the firms depends on the relative importance of these two components of consumers' preferences.

There is also a much smaller empirical literature on durable-goods markets accommodating dynamics on both the demand and supply sides..$^{6}$ Our article builds on Esteban and Shum (2007), who analyzed a durable-goods oligopoly model with secondary markets under the restrictive assumptions of no transaction costs and limited consumer heterogeneity. ${ }^{7}$ Nair (2007) and Goettler and Gordon (2009) estimate dynamic equilibrium models for (respectively) the video game console industry and the PC microprocessors industry. In these two papers, both consumers and firms are forward looking, but there is no secondary market for used goods.

Lastly, since transaction costs lead to inertia in consumers' product choices from one period to the next, our article also relates to studies that model consumers as having (S,s) type replacement problems. ${ }^{8}$ Stolyarov (2002) explains the pattern of used car holdings and trade using a model with competitive primary and secondary markets, in which consumers are heterogeneous and replace their goods infrequently due to transaction costs in the used car market. Gavazza, Lizzeri, and Roketskiy (2012) consider a model of secondary markets with heterogeneous consumers, transaction costs, and exogenous new good supply; the model successfully matches aggregate features of the US and French car markets.

We end this section by noting some limitations of our analysis. First, we abstract away from asymmetric information between buyers and sellers which, as is well known (Akerlof 1970), can cause adverse selection in secondary markets. 9 In our setting, however, asymmetric information is potentially one component which underlies transaction costs. Second, we do not allow firms to choose the durability of their products, as has been done in the planned obsolescence literature. ${ }^{10}$ Third, we do not allow firms to make additional dynamic decisions (such as innovation decisions) ${ }^{11}$

\footnotetext{
${ }^{5}$ Bresnahan (1981); Berry, Levinsohn, and Pakes (1995); Goldberg (1995); and Petrin (2002) estimate static demand-supply models for the automobile industry, where the firms do not internalize the intertemporal linkages between the new and used car markets.

${ }^{6}$ Relatedly, Gul (1987) studies noncooperative collusion in durable goods oligopoly, Carlton and Gertner (1989) examine the effects of mergers in durable goods industries, and Esteban (2002) investigates the equilibrium dynamics in semi-durable goods markets.

${ }^{7}$ Chen, Esteban, and Shum (2008) and (2010) study, respectively, estimation bias and tax rate reforms in a similar framework without transaction costs.

${ }^{8}$ cf. Eberly (1994); Adda and Cooper (2000); and Attanasio (2000).

${ }^{9}$ The subsequent empirical and theoretical literature in this area is very large; see Bond (1982) and Hendel and Lizzeri (1999a) for representative papers.

${ }^{10}$ See Swan (1972); Bulow (1986); Hendel and Lizzeri (1999a); Iizuka (2007); Waldman (1993), (1996), among many others, for models of endogenous depreciation.

${ }^{11} \mathrm{cf}$. Goettler and Gordon (2009).
} 
to better compete with past production. Finally, we model car manufacturers, which are our application, as only selling cars, instead of both selling and leasing them. ${ }^{12}$

\section{Model}

Next, we build a model of a durable goods oligopoly with secondary markets. In the model, consumers incur transaction costs when selling used goods in the secondary market and have heterogeneous valuations. Time is discrete and firms and consumers are infinitely lived, forward looking, and time consistent.

There are two vintages of goods, new and used. Goods of different vintages differ in their characteristics, while goods of the same vintage are homogeneous. After one period of use, new goods become used and remain in this vintage until they die, an event that occurs stochastically. ${ }^{13}$ We index vintages by $j=0,1,2$, where $j=0$ is the outside option of no good, $j=1$ is a new good, and $j=2$ is a used good. For each vintage, we let $\alpha_{j} \geq 0$ denote its product-characteristics index and normalize $\alpha_{0}=0$.

We next model the vintage transition. We let $\delta_{j} \in[0,1]$ denote the probability of stochastic death of a good of vintage $j$. Given our setting, $1 \geq \delta_{2} \geq 0$, while $\delta_{0}=\delta_{1}=0$. For convenience, we define $\delta \equiv \delta_{2}$. We then let $d(j)$ denote the next period's vintage of a good that is currently vintage $j$ and survives one more period of use. Thus, $d(0)=0, d(1)=2$, and $d(2)=2$ if the used good survives. As used goods may not survive, we let $\hat{d}(j)$ denote the next period's vintage distribution of a good that is currently vintage $j$. For $j=2, \hat{d}(2)$ equals 2 with probability $1-\delta$, while it equals 0 with probability $\delta$. For $j=0,1$, simply $\hat{d}(j)=d(j)$.

In what follows, we first formulate the consumers' and firms' problems in partial equilibrium. Subsequently, we impose equilibrium by clearing all markets and formulating correct expectations by consumers and firms.

\section{A. Consumers' Problem}

On the demand side, there is a continuum of infinitely lived consumers with unit mass and generic consumer $i$. Consumers are differentiated in two dimensions. On the one hand, consumers differ in their marginal utility of money, $\gamma$, of which there are $l=1, \ldots, L<\infty$ distinct types in proportions $\pi_{1}, \ldots, \pi_{L}$, with $\sum_{l} \pi_{l}=1$. We let $l_{i}$ denote $i$ 's type and $\gamma_{i}$ denote his marginal utility of money; this is unchanging across time periods and represents a persistent component of preference heterogeneity across consumers. Consumers also experience preference shocks that vary period-by-period. We let $\epsilon_{i t} \equiv\left(\epsilon_{i 0 t}, \epsilon_{i 1 t}, \epsilon_{i 2 t}\right)$ be the vector of preference shocks of consumer $i$ in period $t$, where the shocks are i.i.d. across $(i, j, t) \cdot{ }^{14}$ In our specification of the utility function that follows, $\gamma$ captures vertical differentiation among the new and used goods in the consumers' preferences, while the preference shocks $\epsilon$ allow for time-varying horizontal differentiation.

\footnotetext{
12 Table 2 of Aizcorbe, Starr, and Hickman (2003) indicates that between 4.5 percent and 6.4 percent of households leased automobiles during our sample period.

${ }^{13}$ Following Swan (1972).

${ }^{14}$ In particular, because all the goods in the same vintage are homogeneous, the preference shock $\epsilon_{i j t}$, for consumer $i$, is the same for all goods of a given vintage $j$ (even if these goods are produced by different firms).
} 
Each consumer owns (at most) one good in each period. We let $s_{i t} \in\{0,2\}$ denote the vintage owned by consumer $i$ at the start of period $t$, and $B_{2 t}^{l}$ denote the measure of consumers who are type $l$ and own vintage 2 (a used good) at the beginning of period $t$. Accordingly, $\mathbf{B}_{t}$ is the vector of used goods holdings by consumer types.

In partial equilibrium, consumers make decisions taking into account current and expected future prices, as well as the transaction cost that is incurred if they sell the used good they own. We let $p_{j t}$ be the price of good $j$ in period $t$ and $\mathbf{p}_{t}=\left(p_{0 t}, p_{1 t}, p_{2 t}\right)$ be the corresponding price vector. We set $p_{0 t}=0$ for all $t$. Because of the transaction costs, consumers prefer keeping the good they own to selling and immediately repurchasing the same vintage from the secondary market, making their choices depend both on their type as well as on the vintage owned. ${ }^{15}$ We let $k_{j}$ denote the transaction cost incurred when selling vintage $j$, for $j=0,2$, with $k_{2}=k$ and $k_{0}=0 .{ }^{16}$

Consumer $i$ derives the following utility flows in period $t$. If she keeps her vintage-vintage $s_{i t}$-she derives utility of $\alpha_{s_{i t}}+\epsilon_{i s_{i t} t}$. If she sells it and purchases $j$ as a replacement (which can be the outside option $j=0$ ), her utility is $\alpha_{j}+$ $\gamma_{i} \cdot\left(p_{s_{i t} t}-k_{s_{i t}}-p_{j t}\right)+\epsilon_{i j t}$, where $k_{s_{i t}}$ is the transaction cost in selling $s_{i t}$ defined above. ${ }^{17}$ Finally, if she scraps the good she owns and buys $j$ as a replacement, she obtains utility of $\alpha_{j}-\gamma_{i} p_{j t}+\epsilon_{i j t}$. When comparing the utility flows, the consumer only sells her used good if $p_{s_{i t} t} \geq k_{s_{i t}}$ as otherwise she would prefer to scrap it. This makes the transaction cost a price floor in the secondary market. ${ }^{18}$ We can express compactly consumer $i$ 's utility flow in $t$ as

$$
u\left(a_{i t}, \mathbf{p}_{t}, s_{i t}, \mathbf{\epsilon}_{i t} ; \gamma_{i}\right)=\underbrace{\alpha_{a_{i t}}+\mathbf{1}_{a_{i t} \neq s_{i t}} \cdot \gamma_{i} \cdot\left(\max \left\{p_{s_{i t} t}-k_{s_{i t}}, 0\right\}-p_{a_{i t} t}\right)}_{\equiv \tilde{u}\left(a_{i t}, \mathbf{p}_{t}, s_{i t} ; \gamma_{i}\right)}+\epsilon_{i a_{i t} t},
$$

where $a_{i t} \in\{0,1,2\}$ denotes $i$ 's consumption choice in $t$. We assume each preference shock $\epsilon_{i j t}$ is distributed type I extreme-value, which leads to a number of convenient closed-form expressions in what follows. 19

\footnotetext{
${ }^{15}$ Without transaction costs, consumers' dynamic optimization problems simplify to static decision problems with prices equal to the implicit rental prices (cf. Esteban and Shum 2007).

${ }^{16}$ We assume the magnitude of the consumers' transaction costs is exogenous. Hendel and Lizzeri (1999b) note that the producers can effectively "endogenize" transaction costs by limiting the transferability of warranties. In the car market, which is the application we later focus on in this article, currently warranties are fully transferrable, which is consistent with our specification.

${ }^{17}$ Our application of the model to the car market motivates this lump-sum specification. In the Kelley Blue Book, the implied transaction cost (measured as the difference between the trade-in value and the suggested retail price) appears to be largely constant, even for cars of very different valuations and quality classes. Nevertheless, one component of transactions costs - taxes-is necessary proportional. To account for this proportionality, we also calibrate a model where transaction costs are proportional to the car price (see Section V.B of the online Appendix); the results are qualitatively and quantitatively very similar to those from our baseline specification below.

${ }^{18}$ In our model, a consumer owns only a single good, and must use it. A hybrid model that allows consumers to hold on to a used good, without scrapping it, and yet purchase another good for consumption, would significantly complicate the dynamic behavior of consumers and firms.

${ }^{19}$ With this assumption, our consumer demand model resembles the "dynamic logit" specifications of the dynamic discrete-choice models that started with Miller (1984) and Rust (1987).
} 
We next consider the dynamic maximization problem of each consumer $i$ given $\left(\hat{\mathbf{p}}_{t}, s_{i t}, \boldsymbol{\epsilon}_{i t}\right)$, the state variables that affect this choice. Using $\hat{\mathbf{p}}_{t}$ to denote the vector of prices from $t$ onwards, we write the Bellman equation for consumer $i$ 's dynamic decision problem as

$$
\begin{aligned}
V(1)\left(\hat{\mathbf{p}}_{t}, s_{i t}, \boldsymbol{\epsilon}_{i t} ; \gamma_{i}\right)=\max _{a_{i t}}[ & u\left(a_{i t}, \mathbf{p}_{t}, s_{i t}, \boldsymbol{\epsilon}_{i t} ; \gamma_{i}\right)+\left(1-\delta_{a_{i t}}\right) \beta \tilde{V}\left(\hat{\mathbf{p}}_{t+1}, d\left(a_{i t}\right) ; \gamma_{i}\right) \\
& \left.+\delta_{a_{i t}} \beta \tilde{V}\left(\hat{\mathbf{p}}_{t+1}, 0 ; \gamma_{i}\right)\right]
\end{aligned}
$$

where $\beta \in(0,1)$ is the discount factor, common to consumers and firms, and

$$
\text { (2) } \tilde{V}\left(\hat{\mathbf{p}}_{t}, s_{i t} ; \gamma_{i}\right) \equiv E_{\epsilon} V\left(\hat{\mathbf{p}}_{t}, s_{i t}, \mathbf{\epsilon}_{i t} ; \gamma_{i}\right)
$$$$
=\log \left\{\sum_{j=0,1,2} \exp \left(\tilde{u}\left(j, \mathbf{p}_{t}, s_{i t} ; \gamma_{i}\right)+\left(1-\delta_{j}\right) \beta \tilde{V}\left(\hat{\mathbf{p}}_{t+1}, d(j) ; \gamma_{i}\right)\right)+\delta_{j} \beta \tilde{V}\left(\hat{\mathbf{p}}_{t+1}, 0 ; \gamma_{i}\right)\right\}
$$

is the expected value function before consumer $i$ 's shock is observed, with the latter substitution following from the assumption that the $\epsilon \mathrm{s}$ are extreme-valued. Accordingly, the choice probability of product $j$ by consumer $i$ who owns a vintage $j^{\prime}$ and is of type $l$ takes the multinomial logit form

$$
\begin{aligned}
& q_{j}\left(\mathbf{p}_{t}, j^{\prime}, \hat{\mathbf{p}}_{t+1} ; \gamma_{l}\right)= \\
& \frac{\exp \left(\tilde{u}\left(j, \mathbf{p}_{t}, j^{\prime} ; \gamma_{l}\right)+\left(1-\delta_{j}\right) \beta \tilde{V}\left(\hat{\mathbf{p}}_{t+1}, d(j) ; \gamma_{l}\right)+\delta_{j} \beta \tilde{V}\left(\hat{\mathbf{p}}_{t+1}, 0 ; \gamma_{l}\right)\right)}{\sum_{h=0,1,2} \exp \left(\tilde{u}\left(h, \mathbf{p}_{t}, j^{\prime} ; \gamma_{l}\right)+\left(1-\delta_{h}\right) \beta \tilde{V}\left(\hat{\mathbf{p}}_{t+1}, d(h) ; \gamma_{l}\right)+\delta_{h} \beta \tilde{V}\left(\hat{\mathbf{p}}_{t+1}, 0 ; \gamma_{l}\right)\right)}
\end{aligned}
$$

Aggregate Demand Functions.-We next aggregate up the choices for all consumers to obtain the aggregate quantity demanded for each vintage $j$ in period $t$ as well as the quantity of used goods supplied. We let $Q_{j t}^{D}$, for $j=1,2$, denote the demand for new and used goods in period $t$ and $Q_{j t}^{D l}$ denote the demand by type $l$. The demand functions are then given by, respectively,

$$
\begin{aligned}
Q_{1 t}^{D} & \equiv \sum_{l} Q_{1 t}^{D l}=\sum_{l}\left(B_{0 t}^{l} \cdot q_{1}\left(\mathbf{p}_{t}, 0, \hat{\mathbf{p}}_{t+1} ; \gamma_{l}\right)+B_{2 t}^{l} \cdot q_{1}\left(\mathbf{p}_{t}, 2, \hat{\mathbf{p}}_{t+1} ; \gamma_{l}\right)\right) \\
Q_{2 t}^{D} & \equiv \sum_{l} Q_{2 t}^{D l}=\sum_{l} B_{0 t}^{l} \cdot q_{2}\left(\mathbf{p}_{t}, 0, \hat{\mathbf{p}}_{t+1} ; \gamma_{l}\right) .
\end{aligned}
$$

By construction, we exclude from the demand for used goods those consumers who keep the used good they already own.

As consumers cannot own more than one good, the supply of used goods in the market is given by the goods owned by those consumers buying into other vintages. 
We let $Q_{2 t}^{S}$ denote the supply of used goods in period $t$, which is given by

$$
Q_{2 t}^{S}= \begin{cases}\sum_{l}\left(B_{2 t}^{l} \cdot q_{0}\left(\mathbf{p}_{t}, 2, \hat{\mathbf{p}}_{t+1} ; \gamma_{l}\right)+B_{2 t}^{l} \cdot q_{1}\left(\mathbf{p}_{t}, 2, \hat{\mathbf{p}}_{t+1} ; \gamma_{l}\right)\right) & \text { if } p_{2 t} \geq k \\ 0 & \text { otherwise. }\end{cases}
$$

\section{B. Firms' Problem}

We now turn to the problem of the firms, which, initially, we solve in partial equilibrium by taking as given the inverse demand functions and the law of motion determining the next period's consumers' used goods holdings. We restrict the firms' strategies to be Markov, requiring that the firms' production choices be only functions of the payoff relevant state, which, in our setting, is the vector of used goods holdings by consumer types, given by $\mathbf{B}_{t}$. Then, in every period, firms choose quantities simultaneously to maximize their discounted sum of current and future profits while accounting for the optimality of the future actions. ${ }^{20}$

There are $N$ firms producing homogeneous new goods. For $n=1, \ldots, N$, let $\mathbf{x}_{t}=\left(x_{1 t}, \ldots, x_{N t}\right)$ be the vector of their production choices, and let $\mathbf{x}_{-n t}$ be the subvector containing all elements of $\mathbf{x}_{t}$ but excluding $x_{n t}$. We also assume the marginal cost of production is constant and equal to $c \geq 0$ for all firms.

We let $\mathbf{B}_{t+1}=L\left(\mathbf{x}_{t}, \mathbf{B}_{t}\right)$ be the law of motion of the used goods holdings' vector, and let $P\left(\mathbf{x}_{t}, \mathbf{B}_{t}\right)$ be the inverse demand function of new goods. For the time being, in partial equilibrium, we assume the inverse demand function is only a function of the current state and choice variables, eliminating its dependence on future output which characterizes durable goods problems with forward-looking consumers. In the next section, we show that an inverse demand function with this structure is consistent with a Markov Perfect Equilibrium, in which the equilibrium decision rules (which depend only on current state variables) are recursively substituted into the consumers' forward-looking decision rules.

Given the inverse demand functions $P\left(\mathbf{x}_{t}, \mathbf{B}_{t}\right)$, the law-of-motion $L\left(\mathbf{x}_{t}, \mathbf{B}_{t}\right)$, and the rival firms' production $\mathbf{x}_{-n t}$, the maximization problem of each firm is a dynamic programming problem with state $\mathbf{B}_{t}$. Then, a Markov-perfect equilibrium consists of decision rules $G_{n}(\cdot)$ and value functions $W_{n}(\cdot)$ such that, for all $n=1, \ldots, N$,

$$
G_{n}\left(\mathbf{B}_{t}\right)=\underset{x_{n t}}{\arg \max }\left[\left(P\left(\left(x_{n t}, G_{-n}\left(\mathbf{B}_{t}\right)\right), \mathbf{B}_{t}\right)-c\right) x_{n t}+\beta W_{n}\left(L\left(\left(x_{n t}, G_{-n}\left(\mathbf{B}_{t}\right)\right), \mathbf{B}_{t}\right)\right)\right]
$$

and

$W_{n}\left(\mathbf{B}_{t}\right)=\left(P\left(\left(G_{n}\left(\mathbf{B}_{t}\right), G_{-n}\left(\mathbf{B}_{t}\right)\right), \mathbf{B}_{t}\right)-c\right) G_{n}\left(\mathbf{B}_{t}\right)+\beta W_{n}\left(L\left(\left(G_{n}\left(\mathbf{B}_{t}\right), G_{-n}\left(\mathbf{B}_{t}\right)\right), \mathbf{B}_{t}\right)\right)$

We focus our attention on symmetric equilibrium.

\footnotetext{
${ }^{20}$ Our assumption that the firms choose quantities is supported by several institutional features of the automobile industry, which is our chosen application. Capacities do not appear to be easily adjustable in the automobile industry (cf., Bresnahan and Ramey 1994); moreover, it appears common for car manufacturers to adjust prices to clear inventories by offering rebates or other forms of price discounts toward the end of each model year.
} 


\section{Equilibrium}

In equilibrium, we require:

(i) Primary market clearance: For new goods, $\sum_{n=1, \ldots, N} G_{n}(\mathbf{B})=Q_{1}^{D}$, as defined in the demand equation in (4).

(ii) Secondary market clearance/free disposal: For used goods, $Q_{2}^{D}=Q_{2}^{S}$ if $p_{2}>k$, where $Q_{2}^{D}$ and $Q_{2}^{S}$ are defined in the used goods demand and supply equations (4) and (5), respectively. If $p_{2}=k$, i.e., if the price floor $k$ binds, then $Q_{2}^{S} \geq Q_{2}^{D}$, and the measure of used goods scrapped is $Q_{2}^{S}-Q_{2}^{D} \cdot{ }^{21}$

(iii) Consistency of the inverse demand functions: $\mathbf{p}=P(\mathbf{x}, \mathbf{B})$ satisfies the aggregate demand and supply equations in (4) and $(5)$, where the next period's price is given by $\mathbf{p}^{\prime}=P(G(L(\mathbf{x}, \mathbf{B})), L(\mathbf{x}, \mathbf{B})) \cdot{ }^{22}$ In equilibrium, consumers observe current prices and form rational expectations of future prices consistent with this law of motion.

(iv) Consistency of the law of motion for the durable goods holdings vector: The vector of vintage holdings evolves as:

(6) $\left(B_{1}^{l}\right)^{\prime}=0$,

$$
\begin{aligned}
& \left(B_{2}^{l}\right)^{\prime}=Q_{1}^{D l}+(1-\delta)\left(B_{0 t}^{l} \cdot q_{2}\left(\mathbf{p}_{t}, 0, \hat{\mathbf{p}}_{t+1} ; \gamma_{l}\right)+B_{2 t}^{l} \cdot q_{2}\left(\mathbf{p}_{t}, 2, \hat{\mathbf{p}}_{t+1} ; \gamma_{l}\right)\right), \\
& \left(B_{0}^{l}\right)^{\prime}=1-\left(B_{2}^{l}\right)^{\prime},
\end{aligned}
$$

where $Q_{1}^{D l}$ is defined in the demand equations (4), and the probability $q_{2}\left(\mathbf{p}, \cdot, \mathbf{p}^{\prime} ; \gamma\right)$ is defined in equation (3). We also require that the updating rule equals the law-ofmotion $L(\mathbf{x}, \mathbf{B})$ introduced in the firm's problem.

By focusing on a Markov-perfect equilibrium, we require firms to be time consistent - so that they cannot commit to future production levels that are suboptimal once the future period is reached. Time consistency is also implied by condition (iii) of the equilibrium definition above, which requires that consumers form rational expectations of prices based on optimal future equilibrium behavior.

\section{Calibration}

In order to quantify the effects of secondary markets, we calibrate our model to aggregate data from the US automobile market. Some of the parameter values are set a priori based on data or recent empirical studies, while others are obtained by finding parameter values that give the best fit between the model's steady-state

\footnotetext{
${ }^{21}$ When $p_{2}=k$, an owner of a used good is indifferent between selling her used good and scrapping it. Therefore, in the model we do not need a rationing rule that specifies, when the quantity supplied is greater than the quantity demanded, which suppliers sell their used goods and which scrap them.

${ }^{22}$ Given $P(\cdot), G(\cdot)$, and $L(\cdot)$, all current and future prices are functions of the current state vector $\mathbf{B}$. Therefore, in the general equilibrium specification of the consumers' problem, $V$ and $\tilde{V}$ are also functions of $\mathbf{B}$.
} 
TABle 1-Fixed Parameters

\begin{tabular}{lc}
\hline \hline Discount factor $(\beta)$ & $1 / 1.04$ \\
Number of distinct persistent consumer types $(L)$ & 2 \\
Percentage of type 1 consumers & 50 \\
Percentage of type 2 consumers & 50 \\
Probability of used car quantity depreciation $(\delta)$ & 0.11 \\
Number of firms $(N)$ & 3 \\
\hline
\end{tabular}

values of endogenous variables and the average aggregate values for the US automobile market during the years 1994-2003.

Table 1 summarizes all the parameters that we fix in the calibration exercise. The model's persistent heterogeneity parameters, the $\gamma$ 's, arise from income differences in the population. To keep our study tractable, we approximate the income distribution with two consumer types $(L=2)$, which we label as types 1 and 2, and let each type represent half of the consumer population. Empirically, these types are identified as those with above- and below-median income. Then, the car holdings' vector in this two-vintage, two-type specification of the model has two elements, $B_{2}^{1}$ and $B_{2}^{2}$, which are the used car stocks held by each of the two consumer types.

On the supply side, we consider an oligopoly of three firms producing homogeneous new cars, corresponding to the Big Three US automobile producers (General Motors, Ford, and Chrysler). As is common in the literature, we assume the interest rate to be 4 percent, which corresponds to a discount factor of $\beta=1 / 1.04$.

Although in our model, cars have only two vintages (new and used), the modeling of stochastic death of used cars allows them to live for more than two years. This modeling plays an important role in allowing us to match the observed expected lifetime of a vehicle. In fact, according to the 2001 US National Household Travel Survey (NHTS), the expected lifetime of a vehicle was nine years. In the steady state of our model, the average age of existing cars is

$$
\phi(\delta)=\frac{1 \cdot 1+2 \cdot 1+3 \cdot(1-\delta)+4 \cdot(1-\delta)^{2}+\cdots}{1+1+(1-\delta)+(1-\delta)^{2}+\cdots},
$$

where $\delta \in[0,1]$ is the death probability. We therefore solve $\phi(\delta)=9$ to obtain $\delta=0.11$, which we fix in our computations. ${ }^{23}$ Later, in the robustness checks section (Section IVE), we explore a calibration where $\delta$ is, instead, a free parameter.

The remaining model parameters are calibrated; these are: $\alpha_{1}$, the new car product-characteristics index; $\alpha_{2}$, the used car product-characteristics index; $\gamma_{1}$ (respectively, $\gamma_{2}$ ), the type 1 (2) consumers' marginal utility of money; $c$, the marginal cost of production (identical for all firms); and $k$, the transaction cost parameter. We obtain these values by minimizing the sum of the squared percentage differences between the model's steady-state predictions and the US averages for the following variables: (i) the fraction of above-median income (type 1) and belowmedian income (type 2) consumers who purchase new and used cars; (ii) the new

\footnotetext{
${ }^{23}$ The alternative to modeling stochastic death of used cars would have been to increase the number of vintages, but doing so would make the state space very large, which would heavily increase the computational burden and make the calibration exercise infeasible.
} 
Table 2-Calibrated Parameters

\begin{tabular}{lr}
\hline \hline New car product-characteristics index $\left(\alpha_{1}\right)$ & 1.67 \\
Used car product-characteristics index $\left(\alpha_{2}\right)$ & 0.80 \\
Type 1 consumers' marginal utility of money $\left(\gamma_{1}\right)$ & 1.70 \\
Type 2 consumers' marginal utility of money $\left(\gamma_{2}\right)$ & 2.28 \\
Marginal cost $(c), \$ 10,000$ & 1.90 \\
Transaction cost $(k), \$ 10,000$ & 0.44 \\
\hline
\end{tabular}

Note: Throughout the paper, all monetary numbers are reported in \$10,000 in the year 2003.

and used vehicle prices; and (iii) the firms' markup (the difference between the new vehicle price and the marginal cost, divided by the new vehicle price). For (i) and (ii), the US averages are calculated from the owned vehicle component of the Consumer Expenditure Survey for the years 1994-2003, while (iii) is calculated from the annual reports of the Big Three US automobile producers. All prices are converted to dollars in the year 2003.

Despite having reduced the number of parameters, having dynamics on both the demand and supply sides of the market imposes a heavy computational burden for the calibration exercise. We overcome this hurdle by taking an MPEC approach to calibration. The MPEC approach is a constrained optimization approach to fitting equilibrium models, with constraints that are given by the equilibrium conditions of the consumers' and producers' dynamic optimization problems (more details are contained in the online Appendix). ${ }^{24}$ In our calibration exercise, the main advantage of the MPEC approach is to avoid computing the dynamic equilibrium of the model for every candidate set of parameter values, except for the final set. As a result, we reduce the computational burden and associated computing time considerably.

\section{A. Calibration Results}

Table 2 presents the calibrated values of the free parameters, and Table 3 the corresponding simulated steady-state values alongside the US averages. Table 4 reports steady-state results at the calibrated parameter values. Throughout, all the monetary numbers are reported in $\$ 10,000$ in the year 2003 .

Table 2 shows that the product-characteristics index of new cars $\left(\alpha_{1}=1.67\right)$ is 109 percent higher than that of used cars $\left(\alpha_{2}=0.80\right)$. The type 1 consumers have a lower price sensitivity $(\gamma)$ equal to 1.70 (i.e., a higher taste for quality), while the type 2 consumers have a higher price sensitivity coefficient of 2.28 (a lower taste for quality). Thus, given our calibrated parameter values, gains from trade occur due to the heterogeneity in the consumers' valuation of the goods, in both the persistent and the time-varying terms, and the heterogeneity of the product, in the productcharacteristics' index and/or the product's stochastic death. ${ }^{25}$

The marginal cost parameter is calibrated at 1.90 (\$19,000), which appears to be in the correct range. ${ }^{26}$ The transaction cost parameter $k$ is shown to be calibrated to

\footnotetext{
${ }^{24}$ See also Luo, Pang, and Ralph (1996) for additional details.

${ }^{25}$ It is worth noting that, without transaction costs, heterogeneity in the product's stochastic death alone does not create gains from trade.

${ }^{26}$ Copeland, Dunn, and Hall (2005), for example, reports a lower bound on marginal costs of $\$ 17,693$ (in the year 2000), which corresponds to $\$ 18,905$ in the year 2003 .
} 
Table 3-Steady-State Values at Calibrated Parameters and US Data Averages

\begin{tabular}{lcc}
\hline \hline & Model steady-state values & $\begin{array}{c}\text { US data averages } \\
(1994-2003)^{\mathrm{a}}\end{array}$ \\
\hline $\begin{array}{l}\text { Percentage of type 1 consumers: } \\
\quad \text { who purchase new cars }\end{array}$ & 9.68 & 9.8 \\
$\quad$ who purchase used cars & 17.79 & 18.7 \\
Percentage of type 2 consumers: ${ }^{\mathrm{c}}$ & & \\
$\quad$ who purchase new cars & 4.20 & 4.2 \\
$\quad$ who purchase used cars & 19.28 & 18.6 \\
New vehicle price $(\$ 10,000)$ & 2.30 & 2.3 \\
Used vehicle price $(\$ 10,000)$ & 0.90 & 0.9 \\
Firms' markup & 0.17 & 0.17 \\
\hline
\end{tabular}

Notes:

${ }^{\text {a }}$ Calculated from Consumer Expenditure Survey and annual reports of the Big Three US automobile producers.

${ }^{\mathrm{b}}$ Households with above-median income.

${ }^{\mathrm{c}}$ Households with below-median income.

Table 4-Steady-State Results at Calibrated Parameter Values

\begin{tabular}{lcc}
\hline & Consumers' transition probabilities $\mathrm{P}\left(s_{t} \mid r_{t}\right)^{\mathrm{a}}$ & Type 2 \\
& Type & 0.03 \\
\hline $\mathrm{P}(1 \mid 2)$ & 0.08 & 0.73 \\
$\mathrm{P}(2 \mid 2)^{\mathrm{b}}$ & 0.68 & 0.23 \\
$\mathrm{P}(0 \mid 2)$ & 0.24 & 0.06 \\
$\mathrm{P}(1 \mid 0)$ & 0.13 & 0.50 \\
$\mathrm{P}(2 \mid 0)$ & 0.50 & 0.44 \\
$\mathrm{P}(0 \mid 0)$ & 0.38 & 61.7 \\
$\mathrm{Percentage}$ & 64.4 & \\
\hline
\end{tabular}

Notes:

${ }^{\text {a }} \mathrm{P}\left(s_{t} \mid r_{t}\right)$ is the probability that a consumer who owns $r_{t}$ at the beginning of $t$ chooses $s_{t} .1$ indicates a new car, 2 indicates a used car, and 0 indicates the outside option of no car.

${ }^{\mathrm{b}}$ In the model, all used cars are identical. Therefore, no consumers sell their current used car and buy a different used car in the same period, and $\mathrm{P}(2 \mid 2)$ in the table corresponds to consumers who keep their current used car. In the US data averages, 5.7 percent of type 1 consumers and 4.6 percent of type 2 consumers sell their current used car and buy a different used car in the same year.

equal 0.44 , corresponding to $\$ 4,400$. This is corroborated by the Kelley Blue Book, which indicates that, typically, the difference between the trade-in value of a used car (seller's price for consumers) and its suggested retail value (buyer's price) which may serve as a proxy for the transaction cost-is in the $\$ 3,000-\$ 4,000$ range.

Table 3 reports that in the steady state, 9.68 percent of the type 1 consumers purchase new cars and 17.79 percent purchase used cars, while 4.20 percent of the type 2 consumers purchase new cars and 19.28 percent purchase used cars. Thus, type 1 consumers participate more in the primary market than type 2 consumers do.

This table also reports the markup, which equals 0.17 . While our model has a stripped-down specification of consumer heterogeneity relative to other empirical studies of the automobile market (e.g., Goldberg 1995; Berry, Levinsohn, and Pakes 
1995), our markup figure remains in the same ballpark. ${ }^{27}$ Lastly, this table also shows that the used car price, which equals 0.90 , is greater than the calibrated transaction cost of 0.44 , indicating that used cars are not being scrapped in steady state.

Table 4 provides further characterization of the behavior of the different consumer types. It reports that, in the steady state, 64.4 percent of the type 1 consumers and 61.7 percent of the type 2 ones start next period owning a used car. It also contains the consumers' car ownership transitional probabilities, showing that, unconditionally, the high type consumers (type 1) are more likely to purchase new cars, while the low type consumers are more likely to hold on to their used cars, which is consistent with the observed sorting of the population by income and car vintage in the data.

\section{Counterfactuals: Do Secondary Markets Harm Firms?}

The purpose of our counterfactual experiments is to identify when and how secondary markets may be beneficial to durable goods manufacturers and the role that the different effects - substitution, allocative, and time consistency-may play. In these experiments, we change the transaction cost parameter $k$ while holding all the other parameters fixed at the calibrated parameter values reported in Table 2, and recompute the equilibrium and the steady state. In all experiments, we vary $k$ between 8 , which closes secondary markets, and 0 , which makes them frictionless. For expositional convenience, we measure the effect of $k$ on profits by reporting the percentage changes between $k=8$ and $k=0 .{ }^{28}$

The first panel of Table 5 presents the baseline counterfactual steady-state outcomes, measuring the net effect of opening secondary markets. Relative to $k=8$, opening the secondary market to $k=0$ lowers profits by 35 percent, identifying that at the calibrated parameter values, the secondary market has a negative effect on the firm's profitability. ${ }^{29}$ This effect, however, is not monotonic, reinforcing our intuition that there might be different, countervailing effects at play.

One additional, yet not surprising, observation, which survives throughout our counterfactuals, stems from the first panel in this table. Consumer surplus increases with the opening of secondary markets, from 0.32 to 0.60 as $k$ is decreased from 8 to 0 , as the distortion on the efficient allocation of goods is eliminated. ${ }^{30}$ Although closing the secondary market does also render a positive effect on consumers' surplus as it increases the total car fleet (from 0.65 to 0.80 ), this effect is outweighed by the distortions that transaction costs create in the allocation of goods.

Better understanding these findings requires that we assess the different effects at play and how these may depend on the key parameters and the consumer heterogeneity distributional assumptions. This is the purpose of the counterfactuals that follow. In these counterfactuals, all the effects occur in tandem, but we make changes

\footnotetext{
${ }^{27}$ For example, Berry, Levinsohn, and Pakes (1995) report markups (in 1990) ranging from 0.155 to 0.328 , with an average of 0.239 .

${ }^{28}$ Absolute changes in firms' profits are also reported in all tables.

${ }^{29}$ Section III in the online Appendix reports the behavior of the two types of consumers as the secondary market becomes more active.

${ }^{30}$ In all counterfactuals, total surplus also increases as $k$ is decreased from 8 to 0 .
} 
Table 5-Effects of Opening Secondary Market: Substitution, Allocation, and Time Consistency

\begin{tabular}{|c|c|c|c|c|}
\hline & \multicolumn{4}{|c|}{ Transaction cost $k(\$ 10,000)$} \\
\hline & 8 & 2 & 0.44 & 0 \\
\hline \multicolumn{5}{|l|}{ Panel A. Baseline } \\
\hline New car production per firm ${ }^{a}$ & 0.046 & 0.038 & 0.023 & 0.021 \\
\hline Used car transactions & 0.00 & 0.04 & 0.19 & 0.24 \\
\hline New car price $(\$ 10,000)$ & 2.22 & 2.16 & 2.30 & 2.35 \\
\hline Used car price $(\$ 10,000)^{\mathrm{b}}$ & 8.00 & 2.00 & 0.90 & 0.69 \\
\hline Used car scrappage & 0.07 & 0.04 & 0.00 & 0.00 \\
\hline Consumers who own no cars & 0.20 & 0.20 & 0.30 & 0.35 \\
\hline Consumer surplus $(\$ 10,000)^{\mathrm{d}}$ & 0.32 & 0.35 & 0.50 & 0.60 \\
\hline Profits per firm $(\$ 10,000)$ & 0.015 & 0.010 & 0.009 & $0.010(-0.005,-35 \%)^{\mathrm{c}}$ \\
\hline \multicolumn{5}{|l|}{ Panel B. Full commitment } \\
\hline New car production per firm ${ }^{a}$ & 0.041 & 0.035 & 0.020 & 0.018 \\
\hline Used car transactions & 0.00 & 0.04 & 0.19 & 0.25 \\
\hline New car price $(\$ 10,000)$ & 2.46 & 2.25 & 3.21 & 3.82 \\
\hline Used car price $(\$ 10,000)^{\mathrm{b}}$ & 8.00 & 2.00 & 1.70 & 2.01 \\
\hline Used car scrappage & 0.05 & 0.03 & 0.00 & 0.00 \\
\hline Consumers who own no cars & 0.21 & 0.21 & 0.39 & 0.45 \\
\hline Consumer surplus $(\$ 10,000)^{\mathrm{d}}$ & 0.29 & 0.34 & 0.46 & 0.53 \\
\hline Profits per firm $(\$ 10,000)$ & 0.023 & 0.012 & 0.026 & $0.035(+0.012,+52 \%)^{\mathrm{c}}$ \\
\hline \multicolumn{5}{|c|}{ Panel C. Full commitment and reduced preference heterogeneity $\left(\gamma_{1}=\gamma_{2}=2.28, \operatorname{Var}(\varepsilon)=1 / 4 \times \pi^{2} / 6\right)$} \\
\hline New car production per firm ${ }^{\mathrm{a}}$ & 0.028 & 0.027 & 0.025 & 0.022 \\
\hline Used car transactions & 0.00 & 0.00 & 0.12 & 0.24 \\
\hline New car price $(\$ 10,000)$ & 2.61 & 2.61 & 2.58 & 2.71 \\
\hline Used car price $(\$ 10,000)^{\mathrm{b}}$ & 8.13 & 2.68 & 1.82 & 1.67 \\
\hline Used car scrappage & 0.00 & 0.00 & 0.00 & 0.00 \\
\hline Consumers who own no cars & 0.17 & 0.17 & 0.25 & 0.35 \\
\hline Consumer surplus $(\$ 10,000)^{\mathrm{d}}$ & 0.14 & 0.15 & 0.20 & 0.27 \\
\hline Profits per firm $(\$ 10,000)$ & 0.019 & 0.019 & 0.017 & $0.017(-0.002,-11 \%)^{\mathrm{c}}$ \\
\hline
\end{tabular}

Notes: The calibrated transaction cost is $k=0.44$.

${ }^{a}$ New car production per firm, used car transactions, used car scrappage, and consumers who own no cars are all measured against the consumer population, which is normalized to one.

${ }^{\mathrm{b}}$ Because of the type I extreme value distribution of $\varepsilon$, there is a positive, though small, measure of buyers of used cars even at a very high used car price.

${ }^{\mathrm{c}}$ First number in parentheses: change in profits from $k=8$ to $k=0$; second number in parentheses: percentage change in profits from $k=8$ to $k=0$.

${ }^{\mathrm{d}}$ Consumers' utilities are converted to monetary terms using their respective $\gamma \mathrm{s}$.

which highlight one effect more than the others, given the workings of the model. In this way, we highlight the different effects in turn.

\section{A. Assessing the Multiple Effects of Secondary Markets}

First, we focus on the substitution and allocative effects. To distinguish these effects from the time consistency effect, we compute the solution to a full commitment scenario in which each firm commits once and for all to a constant sequence of production (details are contained in the online Appendix). This scenario eliminates the time consistency effect, so that the change in profits from opening secondary markets is only determined by the substitution and allocative effects.

The second panel of Table 5 reports the results. It shows that opening the secondary market from $k=8$ to $k=0$ increases firms' profits by 52 percent. Therefore, when the time consistency effect is eliminated, the positive allocative effect of 
opening the secondary market is sufficiently large to outweigh the negative substitution effect due to the increased tradability of used cars.

We can now go back and compare panel A (the time consistent solution) and panel B (full commitment solution) to evaluate the time consistency effect. In the commitment scenario, profits increase by 52 percent from opening secondary markets; without commitment, however, profits decrease by 35 percent. By removing the firms' ability to commit to cutting back future output, the time consistent solution yields more output (for all values of $k$ ), and thus a larger used goods stock, than the full commitment one. The negative impact of the implied increase in the used goods stock (the time consistency effect) is largest when the secondary market works without frictions as it magnifies the substitution possibilities with the used goods stock.

It is interesting to compare prices and output between panels A and B in Table 5. With a closed secondary market $(k=8)$, firm output increases from 0.041 to 0.046 when the solutions change from full commitment to no commitment, while the new goods price decreases from 2.46 to 2.22 . In contrast, with a frictionless secondary market $(k=0)$, output increases from 0.018 to 0.021 when the solutions change from full commitment to no commitment, while the new goods price exhibits a much larger change from 3.82 to 2.35 . As we see here, a small change in output has a much larger effect on the new goods' prices when the secondary markets are open than closed. In other words, active secondary markets magnify the effect of changes in production on new goods prices because these prices capitalize market conditions; in this way, secondary markets make the new car producers' demand curve less elastic.

Going further, in the third panel of Table 5 we consider a scenario in which firms can commit but in which consumer heterogeneity is reduced-we make the persistent component $(\gamma)$ identical between the two types and reduce the variance of the time-varying component $(\epsilon)$. By reducing the range of the consumer heterogeneity in this way, we reduce the scope for allocative gains of secondary markets. Accordingly, opening the secondary market decreases profits by 11 percent.

The findings above illustrate a subtle relationship between consumer preferences and the substitution effect. Even when secondary markets are closed, the substitution effect does not go away; indeed, ownership of the used good prevents consumers from returning to the primary market—in this way, then, consumers who own used goods can still substitute between these goods. These substitution possibilities are weaker when consumers' preferences are less persistent, because in this case, owners of used cars will be more often dissatisfied with their used car and willing to return to the primary market. Thus, less persistent preferences further increase the gains from closing the secondary market; this is also evident in the next set of counterfactuals, in which we manipulate the parameters characterizing the consumers' preference heterogeneity. 31

\footnotetext{
${ }^{31}$ Prices and quantities in panel $\mathrm{C}$ cannot be compared with their counterparts in panels $\mathrm{A}$ and $\mathrm{B}$ as, in this counterfactual, the demand function changes because we vary the underlying preference heterogeneity. Instead, when full commitment and no commitment solutions are compared, the demand structure remains unchanged.
} 


\section{B. Assessing Consumer Heterogeneity}

The magnitude of the substitution effect, and therefore the gains from closing the secondary market, depend on the underlying sources of preference heterogeneity. As we discussed above, the substitution effect hurts firms by magnifying the effect of the used car stock on new car prices. Furthermore, as we also saw above, changes in the relative importance of the persistence of consumer preferences affect the magnitude of the substitution possibilities even when the secondary market is closed, and thus affect the gains from closing the secondary market.

The counterfactuals here reinforce the above findings. The second panel of Table 6 reports results for the baseline case, in which the scale parameter of the type I extreme value distribution for $\epsilon_{i j t}$ is normalized to 1 and, hence, $\operatorname{Var}\left(\epsilon_{i j t}\right)=\pi^{2} / 6 .{ }^{32}$ In the first panel, the variance is smaller at $\operatorname{Var}\left(\epsilon_{i j t}\right)=3 / 4 \times \pi^{2} / 6$, and in the third panel, the variance is larger at $\operatorname{Var}\left(\epsilon_{i j t}\right)=5 / 4 \times \pi^{2} / 6$ (the mean is normalized to 0 throughout). Here we find that, consistent with the discussion above, as the variance of $\epsilon_{i j t}$ is increased (which makes consumer preferences relatively less persistent), the loss in profits from opening the secondary market becomes larger. Specifically, from $k=8$ to $k=0$, firms' profits decrease by 35 percent at the baseline variance, compared to a smaller 29 percent at the decreased variance and a larger 40 percent at the increased variance.

In the online Appendix, we further examine the role of consumer heterogeneity by considering alternative specifications of the $\gamma \mathrm{s}$ and the $\alpha \mathrm{s}$. In one of them, we vary consumers' persistent heterogeneity by changing the $\gamma \mathbf{s}$ (reported in Table A7). We find that less persistent heterogeneity limits the allocative gains and enhances the substitution effect, decreasing the returns from opening the secondary market, whereas more persistent heterogeneity increases them.

\section{Assessing Market Structure}

We next consider the interaction between the secondary market and market structure (i.e., the number of primary market competitors). As we will see, this counterfactual, together with the ones that follow, directly affects the size of the secondary market and therefore exacerbates its negative substitution effect.

As in a static Cournot setting, our oligopolistic firms overproduce relative to the optimal industry level because they do not internalize the negative externality that their own output creates on other firms' profits. As the number of firms increases, this Cournot externality worsens. The resulting increase in output also leads to an increase in the stock of used goods, which reinforces the substitution effect and makes the closing of the secondary market more desirable for firms.

The results in Table 7 support our intuition, showing that, as the market becomes less concentrated, opening the secondary market decreases firms' profits by a larger amount. The first panel shows that opening secondary markets decreases profits by 35 percent in the baseline case (with triopoly), whereas in a duopoly (the second panel), profits decrease by only 23 percent. If the firm is a monopolist (the third

\footnotetext{
${ }^{32}$ See Section 2.10.4 in Anderson, de Palma, and Thisse (1992).
} 
Table 6-Effects of Opening Secondary Market: Assessing Variance of Taste Shocks

\begin{tabular}{|c|c|c|c|c|}
\hline & \multicolumn{4}{|c|}{ Transaction cost $k(\$ 10,000)$} \\
\hline & 8 & 2 & 0.44 & 0 \\
\hline \multicolumn{5}{|c|}{ Smaller variance: $\operatorname{Var}(\varepsilon)=3 / 4 \times \pi^{2} / 6^{\mathrm{a}}$} \\
\hline New car production per firm ${ }^{b}$ & 0.041 & 0.034 & 0.024 & 0.023 \\
\hline Used car transactions & 0.00 & 0.03 & 0.17 & 0.24 \\
\hline New car price $(\$ 10,000)$ & 2.19 & 2.15 & 2.24 & 2.28 \\
\hline Used car price $(\$ 10,000)^{\mathrm{c}}$ & 8.00 & 2.00 & 1.00 & 0.76 \\
\hline Used car scrappage & 0.05 & 0.02 & 0.00 & 0.00 \\
\hline Consumers who own no cars & 0.16 & 0.17 & 0.26 & 0.32 \\
\hline Consumer surplus $(\$ 10,000)^{\mathrm{e}}$ & 0.30 & 0.32 & 0.45 & 0.54 \\
\hline Profits per firm $(\$ 10,000)$ & 0.012 & 0.008 & 0.008 & $0.008(-0.004,-29 \%)^{\mathrm{d}}$ \\
\hline \multicolumn{5}{|l|}{ Baseline: $\operatorname{Var}(\varepsilon)=\pi^{2} / 6$} \\
\hline New car production per firm ${ }^{b}$ & 0.046 & 0.038 & 0.023 & 0.021 \\
\hline Used car transactions & 0.00 & 0.04 & 0.19 & 0.24 \\
\hline New car price $(\$ 10,000)$ & 2.22 & 2.16 & 2.30 & 2.35 \\
\hline Used car price $(\$ 10,000)^{\mathrm{c}}$ & 8.00 & 2.00 & 0.90 & 0.69 \\
\hline Used car scrappage & 0.07 & 0.04 & 0.00 & 0.00 \\
\hline Consumers who own no cars & 0.20 & 0.20 & 0.30 & 0.35 \\
\hline Consumer surplus $(\$ 10,000)^{\mathrm{e}}$ & 0.32 & 0.35 & 0.50 & 0.60 \\
\hline Profits per firm $(\$ 10,000)$ & 0.015 & 0.010 & 0.009 & $0.010(-0.005,-35 \%)^{\mathrm{d}}$ \\
\hline \multicolumn{5}{|c|}{ Larger variance: $\operatorname{Var}(\varepsilon)=5 / 4 \times \pi^{2} / 6$} \\
\hline New car production per firm ${ }^{\mathrm{b}}$ & 0.051 & 0.042 & 0.022 & 0.021 \\
\hline Used car transactions & 0.00 & 0.05 & 0.19 & 0.25 \\
\hline New car price $(\$ 10,000)$ & 2.25 & 2.18 & 2.36 & 2.42 \\
\hline Used car price $(\$ 10,000)^{\mathrm{c}}$ & 8.00 & 2.00 & 0.83 & 0.63 \\
\hline Used car scrappage & 0.08 & 0.05 & 0.00 & 0.00 \\
\hline Consumers who own no cars & 0.22 & 0.23 & 0.33 & 0.38 \\
\hline Consumer surplus $(\$ 10,000)^{\mathrm{e}}$ & 0.34 & 0.39 & 0.55 & 0.65 \\
\hline Profits per firm $(\$ 10,000)$ & 0.017 & 0.011 & 0.010 & $0.011(-0.007,-40 \%)^{\mathrm{d}}$ \\
\hline
\end{tabular}

Notes: The calibrated transaction cost is $k=0.44$.

${ }^{\mathrm{a}} \varepsilon$ is a consumer's idiosyncratic taste shock.

${ }^{\mathrm{b}} \mathrm{New}$ car production per firm, used car transactions, used car scrappage, and consumers who own no cars are all measured against the consumer population, which is normalized to one.

${ }^{\mathrm{c}}$ Because of the type I extreme value distribution of $\varepsilon$, there is a positive, though small, measure of buyers of used cars even at a very high used car price.

${ }^{\mathrm{d}}$ First number in parentheses: change in profits from $k=8$ to $k=0$; second number in parentheses: percentage change in profits from $k=8$ to $k=0$.

'Consumers' utilities are converted to monetary terms using their respective $\gamma \mathrm{s}$.

panel), however, opening the secondary market increases its profits by 18 percent: when the oligopolistic externality is eliminated, a monopolist prefers frictionless secondary markets. ${ }^{33}$ In the three panels, we see that when secondary markets are closed, new goods prices do not change by much, while output is increased, which reinforces the argument that closing the secondary market mitigates the negative substitution with past production.

Consistent with what we saw in the previous counterfactuals, the comparison across the panels in Table 7 shows that a small change in output has a much larger effect on the new goods' price when the secondary markets are open than

\footnotetext{
${ }^{33}$ It is worth noting that the comparison of the three panels shows that the detrimental effect of secondary markets is not increasing in absolute value in the number of firms, although it is increasing in percentage terms.
} 
Table 7-Effects of Opening Secondary Market: Assessing Market Structure

\begin{tabular}{|c|c|c|c|c|}
\hline & \multicolumn{4}{|c|}{ Transaction cost $k(\$ 10,000)$} \\
\hline & 8 & 2 & 0.44 & 0 \\
\hline \multicolumn{5}{|l|}{ Baseline: $N=3^{\mathrm{a}}$} \\
\hline New car production per firm ${ }^{b}$ & 0.046 & 0.038 & 0.023 & 0.021 \\
\hline Used car transactions & 0.00 & 0.04 & 0.19 & 0.24 \\
\hline New car price $(\$ 10,000)$ & 2.22 & 2.16 & 2.30 & 2.35 \\
\hline Used car price $(\$ 10,000)^{\mathrm{c}}$ & 8.00 & 2.00 & 0.90 & 0.69 \\
\hline Used car scrappage & 0.07 & 0.04 & 0.00 & 0.00 \\
\hline Consumers who own no cars & 0.20 & 0.20 & 0.30 & 0.35 \\
\hline Consumer surplus $(\$ 10,000)^{\mathrm{e}}$ & 0.32 & 0.35 & 0.50 & 0.60 \\
\hline Profits per firm $(\$ 10,000)$ & 0.015 & 0.010 & 0.009 & $0.010(-0.005,-35 \%)^{\mathrm{d}}$ \\
\hline \multicolumn{5}{|l|}{ Duopoly: $N=2$} \\
\hline New car production per firm ${ }^{b}$ & 0.062 & 0.048 & 0.034 & 0.032 \\
\hline Used car transactions & 0.00 & 0.05 & 0.19 & 0.24 \\
\hline New car price $(\$ 10,000)$ & 2.43 & 2.34 & 2.61 & 2.70 \\
\hline Used car price $(\$ 10,000)^{\mathrm{c}}$ & 8.00 & 2.00 & 1.18 & 1.00 \\
\hline Used car scrappage & 0.05 & 0.02 & 0.00 & 0.00 \\
\hline Consumers who own no cars & 0.21 & 0.21 & 0.31 & 0.36 \\
\hline Consumer surplus $(\$ 10,000)^{\mathrm{e}}$ & 0.29 & 0.33 & 0.48 & 0.57 \\
\hline Profits per firm $(\$ 10,000)$ & 0.033 & 0.021 & 0.024 & $0.025(-0.008,-23 \%)^{\mathrm{d}}$ \\
\hline \multicolumn{5}{|l|}{ Monopoly: $N=1$} \\
\hline New car production per firm ${ }^{b}$ & 0.085 & 0.066 & 0.057 & 0.053 \\
\hline Used car transactions & 0.00 & 0.06 & 0.20 & 0.25 \\
\hline New car price $(\$ 10,000)$ & 3.31 & 3.50 & 4.07 & 4.54 \\
\hline Used car price $(\$ 10,000)^{\mathrm{c}}$ & 8.00 & 2.80 & 2.46 & 2.65 \\
\hline Used car scrappage & 0.02 & 0.00 & 0.00 & 0.00 \\
\hline Consumers who own no cars & 0.29 & 0.33 & 0.43 & 0.46 \\
\hline Consumer surplus $(\$ 10,000)^{\mathrm{e}}$ & 0.20 & 0.24 & 0.38 & 0.45 \\
\hline Profits per firm $(\$ 10,000)$ & 0.120 & 0.106 & 0.123 & $0.141(+0.021,+18 \%)^{\mathrm{d}}$ \\
\hline
\end{tabular}

Notes: The calibrated transaction cost is $k=0.44$.

${ }^{\text {a }} N$ is the number of firms.

${ }^{\mathrm{b}}$ New car production per firm, used car transactions, used car scrappage, and consumers who own no cars are all measured against the consumer population, which is normalized to one.

${ }^{\mathrm{c}}$ Because of the type I extreme value distribution of $\varepsilon$, there is a positive, though small, measure of buyers of used cars even at a very high used car price.

${ }^{\mathrm{d}}$ First number in parentheses: change in profits from $k=8$ to $k=0$; second number in parentheses: percentage change in profits from $k=8$ to $k=0$.

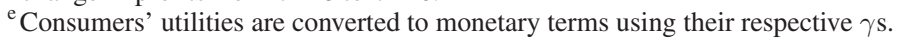

when they are closed. With a closed secondary market $(k=8)$, aggregate output decreases from 0.139 to 0.085 when the market structure changes from triopoly to monopoly, while the new goods price increases from 2.22 to 3.31. In contrast, with a frictionless secondary market $(k=0)$, aggregate output decreases from 0.064 to 0.053 , while the new goods price exhibits a much large change from 2.35 to 4.54 . This comparison again shows that active secondary markets magnify the effect of changes in production on new goods price, leading to a less elastic new car demand curve.

The actual number of firms in the automobile industry exceeds three, as assumed in our baseline simulations. An extrapolation of the results here suggests that, all else equal, with more firms, the secondary market becomes less desirable for firms. 


\section{Assessing Product Durability}

Here we consider the role of product durability in determining firms' losses or gains from opening secondary markets. Intuitively, by increasing durability, we are increasing the used goods stock, which should once more make the secondary market less desirable for firms because of an exacerbated substitution effect. Table 8 contains results from counterfactuals where we vary $\delta$, the per-period death probability of a used car. The results in Table 8 show that opening secondary markets hurts firms more severely as the product becomes more durable. In the first panel, durability is increased by reducing the death probability to $\delta=0.05$. In that case, decreasing transaction costs from 8 to 0 reduces profits by 76 percent. This shows how an increase in durability increases the stock of used cars against which the firms compete, exacerbating the substitution effect when secondary markets are open. Similarly, when durability is reduced by increasing $\delta$ to 0.25 (the third panel), the substitution effect is diminished and each firm's profits actually increase by 11 percent if transaction costs are reduced from 8 to 0 , so the firms would prefer secondary markets to be frictionless. ${ }^{34}$

Remark (Endogenous Durability):-The computational complexity of our current model makes it infeasible to endogenize firms' durability choices. Nonetheless, our framework can shed some light on the problem of planned obsolescence. Using Table 8 and comparing all profits for all values of $k$, we observe that making cars less durable (by increasing $\delta$ ) increases firms' profits, and that the magnitude of the increase is larger if the secondary market is more active. ${ }^{35}$ For example, increasing $\delta$ from 0.11 (the baseline value) to 0.25 increases the firms' profits by 14 percent when the secondary market is closed $(k=8)$, but it increases the firms' profits by a much more substantial 96 percent when the secondary market is open $(k=0)$. These results suggest that when the secondary market becomes more active, firms have a stronger incentive to make their cars less durable. ${ }^{36}$

Remark (Two Vintages):- The assumption that there are only two vintages of cars is made mainly to enable the computation of the model. With more vintages, the different effects of secondary markets will still operate, but their magnitudes might change. Importantly, the magnitude of the allocative effect should increase as

\footnotetext{
${ }^{34}$ It is worth noting that the argument comparing prices with and without secondary markets as we increase the used goods stock cannot be applied here as the underlying product and demand heterogeneity is changed across simulations, resulting in different inverse demand functions.

35 We have also computed profits for all the $(\delta, k)$ combinations with $\delta \in\{0.05,0.07, \ldots, 0.25\}$ and $k \in\{0,0.5,1, \ldots, 8\}$, and these findings are robust.

${ }^{36}$ Some anecdotal evidence supports this result. A 2005 report by the US Government Accountability Office states that, coincident with the rise in Internet retailing of books, textbook publishers "generally agreed that the revision cycle for many books is 3 to 4 years, compared with 4 to 5 years that were standard 10 to 20 years ago [...]" (From GAO 2005, p. 3.) Nevertheless, the textbook and the automobile markets do differ in one important aspect, in that textbooks provide utility to a given consumer primarily for only one period, while automobiles provide utility in all periods of ownership. A model of the textbook market, therefore, would require accounting for the entry and exit of consumers. In our setting, the time-varying component of consumers' preferences only plays partially (and indirectly) this role.
} 
Table 8-Effects of Opening Secondary Market: Assessing Durability

\begin{tabular}{|c|c|c|c|c|}
\hline & \multicolumn{4}{|c|}{ Transaction cost $k(\$ 10,000)$} \\
\hline & 8 & 2 & 0.44 & 0 \\
\hline \multicolumn{5}{|l|}{ More durability: $\delta=0.05^{\mathrm{a}}$} \\
\hline New car production per firm ${ }^{\mathrm{b}}$ & 0.033 & 0.029 & 0.013 & 0.011 \\
\hline Used car transactions & 0.00 & 0.03 & 0.16 & 0.23 \\
\hline New car price $(\$ 10,000)$ & 2.26 & 2.16 & 2.14 & 2.15 \\
\hline Used car price $(\$ 10,000)^{\mathrm{c}}$ & 8.00 & 2.00 & 0.46 & 0.14 \\
\hline Used car scrappage & 0.06 & 0.05 & 0.00 & 0.00 \\
\hline Consumers who own no cars & 0.11 & 0.13 & 0.23 & 0.31 \\
\hline Consumer surplus $(\$ 10,000)^{\mathrm{e}}$ & 0.38 & 0.40 & 0.53 & 0.62 \\
\hline Profits per firm $(\$ 10,000)$ & 0.011 & 0.007 & 0.003 & $0.003(-0.009,-76 \%)^{\mathrm{d}}$ \\
\hline \multicolumn{5}{|l|}{ Baseline: $\delta=0.11$} \\
\hline New car production per firm ${ }^{\mathrm{b}}$ & 0.046 & 0.038 & 0.023 & 0.021 \\
\hline Used car transactions & 0.00 & 0.04 & 0.19 & 0.24 \\
\hline New car price $(\$ 10,000)$ & 2.22 & 2.16 & 2.30 & 2.35 \\
\hline Used car price $(\$ 10,000)^{\mathrm{c}}$ & 8.00 & 2.00 & 0.90 & 0.69 \\
\hline Used car scrappage & 0.07 & 0.04 & 0.00 & 0.00 \\
\hline Consumers who own no cars & 0.20 & 0.20 & 0.30 & 0.35 \\
\hline Consumer surplus $(\$ 10,000)^{\mathrm{e}}$ & 0.32 & 0.35 & 0.50 & 0.60 \\
\hline Profits per firm $(\$ 10,000)$ & 0.015 & 0.010 & 0.009 & $0.010(-0.005,-35 \%)^{\mathrm{d}}$ \\
\hline \multicolumn{5}{|l|}{ Less durability: $\delta=0.25$} \\
\hline New car production per firm ${ }^{\mathrm{b}}$ & 0.061 & 0.051 & 0.041 & 0.041 \\
\hline Used car transactions & 0.00 & 0.05 & 0.20 & 0.25 \\
\hline New car price $(\$ 10,000)$ & 2.18 & 2.16 & 2.31 & 2.36 \\
\hline Used car price $(\$ 10,000)^{\mathrm{c}}$ & 8.00 & 2.00 & 1.15 & 0.97 \\
\hline Used car scrappage & 0.07 & 0.03 & 0.00 & 0.00 \\
\hline Consumers who own no cars & 0.39 & 0.37 & 0.38 & 0.38 \\
\hline Consumer surplus $(\$ 10,000)^{\mathrm{e}}$ & 0.23 & 0.26 & 0.43 & 0.52 \\
\hline Profits per firm $(\$ 10,000)$ & 0.017 & 0.013 & 0.017 & $0.019(+0.002,+11 \%)^{\mathrm{d}}$ \\
\hline
\end{tabular}

Notes: The calibrated transaction cost is $k=0.44$.

${ }^{\mathrm{a}} \delta$ is the probability of used car depreciation.

${ }^{\mathrm{b}} \mathrm{New}$ car production per firm, used car transactions, used car scrappage, and consumers who own no cars are all measured against the consumer population, which is normalized to one.

${ }^{\mathrm{c}}$ Because of the type I extreme value distribution of $\varepsilon$, there is a positive, though small, measure of buyers of used cars even at a very high used car price.

${ }^{\mathrm{d}}$ First number in parentheses: change in profits from $k=8$ to $k=0$; second number in parentheses: percentage change in profits from $k=8$ to $k=0$.

${ }^{\text {e }}$ Consumers' utilities are converted to monetary terms using their respective $\gamma \mathrm{s}$.

more product heterogeneity enhances the efficiency gains from better sorting. This increase could offset our finding that firms prefer closed secondary markets.

\section{E. Robustness Checks and Alternative Specifications}

In the online Appendix, we also present results for several robustness checks and alternative specifications, which we briefly summarize below.

Although in Tables 6 and 8 we report results for only three values of $\operatorname{Var}(\epsilon)$ and three values of $\delta$, respectively, we have extensively varied the parameter values, and our findings are robust. In the online Appendix we present figures that plot the counterfactual results as we let $\delta$ and $\operatorname{Var}(\epsilon)$ take on a broader range of values; the main patterns we observe from Tables 6 and 8 are robust, even at extreme values such as when $\delta$ is close to 1 and when $\operatorname{Var}(\epsilon)$ is close to 0 . 
We also consider alternative specifications of key components of the model. First, we make the transaction cost in the secondary market proportional to the used car price rather than fixed. The calibrated parameter values (and accordingly the counterfactuals) are very similar to those in the baseline specification. ${ }^{37}$

Second, we enhance the accounting of persistent heterogeneity of consumer types by approximating the income distribution by three, not two, types. The results show that our main findings are robust as firms prefer to close secondary markets; nonetheless, the magnitude of the firms' loss due to the secondary market is smaller, which suggests that approximating the distribution with two types may understate the allocative benefits of secondary markets.

Third, we replicate all the counterfactual experiments in the context of a monopolistic primary market. Although the reduced output in this case mitigates the substitution effect and enhances the benefits from opening the secondary market, the directions of the remaining first-order effects are qualitatively unchanged, giving robustness to the triopoly counterfactuals.

Fourth, we also consider the case where firms lease, not sell, new and used cars. As shown in Hendel and Lizzeri (1999b), the leasing and full commitment problems may not be equivalent since the former allows the firm to scrap part of its used car stock. Table A12 in the online Appendix shows how, in our calibrated model, the firm effectively uses scrappage to control the stock, obtaining an additional significant gain in profits. Furthermore, comparing the leasing equilibrium to the baseline (sales without commitment), we find that the leasing equilibrium results in lower new car production, more consumers who own no cars, lower consumer surplus, and much higher profits for the firms, all consistent with the theoretical models.

When firms sell with full commitment, new car prices remain in the same range as in our main calibration results, while when they lease they do not. (Indeed, the leasing prices reported in Table A12 are higher than the lease prices generally observed in the United States). This comparison highlights the optimality of firms' scrappage when cars are leased, not sold: when firms have control over the used goods stock, in equilibrium, they scrap part of it, and this serves to prop up the lease prices. Interestingly, this finding is consistent with our previous result that small changes in output have a large effect on new goods prices when the secondary market is open as the effects of these changes are magnified through the used goods stock.

Lastly, we conduct an alternative calibration which adds the nonownership moments. In the baseline of the article, we fix $\delta$ at 0.11 to match the observed expected lifetime of a vehicle. In this new calibration, we take an alternative approach and fix $\delta$ at 0.095 to match the observed aggregate nonownership: $\delta=0.095$ satisfies nonownership $=1-D_{1}-D_{1} / \delta$ (where $D_{1}$ is the measure of consumers who purchase new cars), using US data averages. Moreover, we add two extra moments to match: percentage of type 1 consumers who do not own cars, and percentage of type 2 consumers who do not own cars. The results are reported in Tables A13-A15 in the online Appendix. Although there are small quantitative differences, the findings are consistent with our previous results. Before profits decrease by 35 percent $(0.005$ in

\footnotetext{
${ }^{37}$ For $k=0(k=8)$, the actual specification of the transaction cost has to be irrelevant because it is equal to zero (secondary market transactions stop taking place).
} 
absolute value) when opening secondary markets, now they decrease by 40 percent (0.006).

\section{Summary and Conclusions}

To investigate how the tradability of durable goods in secondary markets affects firms' behavior and profits, we develop a dynamic equilibrium model of durable goods oligopoly, in which consumers face lumpy costs of transacting in the secondary markets and respond by buying and selling infrequently. Both sides of the market-firms and consumers-are forward looking. We calibrate the model to match aggregate data from the American automobile industry and obtain a good fit.

In our model, the key element that helps us isolate the effects of secondary markets on durable-goods manufacturers is the transaction cost parameter. Using the calibrated version of the model, we run counterfactuals in which we vary the magnitude of transaction costs, to measure the effects of the secondary market on firms. On the whole, the negative effects of secondary markets dominate: at the preferred parameter values, opening the secondary market from closed to frictionless lowers the profits of the new car manufacturers by 35 percent.

The important takeaway from our findings, however, is that secondary markets have multiple countervailing implications for firms' profitability. As the magnitude of these effects depends on the underlying parameter values and thus the particulars of the industry and market considered, the overall effect cannot be generally signed and remains an empirical question. What we found in this paper is that changes that (indirectly) increase the size of the used goods stock, such as increases in the durability of the product, increases in the number of firms, or the removal of the firms' ability to commit, also decrease the profitability of opening the secondary market. On the other hand, changes in demand heterogeneity that magnify the importance of past decisions increase the relative gains of opening the secondary market.

Lastly, we reiterate the caveat that we have had to make several simplifying assumptions in this article to facilitate its computation. Nevertheless, one general policy implication which arises from our findings is the importance of properly accounting for market structure, secondary markets, and the underlying product and demand heterogeneity in analyses of durable good markets. If, for example, the goal is to design a "bailout" plan of the automobile industry, the effects on firms from modifying transaction costs in the secondary market could be sizable. Policies that directly or indirectly affect these costs (for example, sales taxes or scrappage subsidies) may have nontrivial effects on firms' behavior and performance.

\section{REFERENCES}

Adda, Jerome, and Russell Cooper. 2000. "Balladurette and Juppette: A Discrete Analysis of Scrapping Subsidies.” Journal of Political Economy 108 (4): 778-806.

Aizcorbe, Ana, Martha Starr, and James T. Hickman. 2003. "The Replacement Demand for Motor Vehicles: Evidence from the Survey of Consumer Finances." Board of Governors of the Federal Reserve System (U.S.), Finance and Economics Discussion Series: 2003-44.

Akerlof, George A. 1970. "The Market for 'Lemons': Quality Uncertainty and the Market Mechanism." Quarterly Journal of Economics 84 (3): 488-500.

Anderson, Simon P., Andre de Palma, and Jacques-Francois Thisse. 1992. Discrete Choice Theory of Product Differentiation. Cambridge, MA: MIT Press. 
Anderson, Simon P., and Victor A. Ginsburgh. 1994. "Price Discrimination via Second-Hand Markets." European Economic Review 38 (1): 23-44.

Areeda, Phillip E., and Louis Kaplow. 1988. Antitrust Analysis: Problems, Text, Cases. New York: Little, Brown, and Company.

Attanasio, Orazio P. 2000. "Consumer Durables and Inertial Behaviour: Estimation and Aggregation of (S, s) Rules for Automobile Purchases.” Review of Economic Studies 67 (4): 667-96.

-Berry, Steven, James Levinsohn, and Ariel Pakes. 1995. "Automobile Prices in Market Equilibrium." Econometrica 63 (4): 841-90.

Bond, Eric W. 1982. "A Direct Test of the 'Lemons' Model: The Market for Used Pickup Trucks." American Economic Review 72 (4): 836-40.

Bresnahan, Timothy F. 1981. "Departures from Marginal-Cost Pricing in the American Automobile Industry: Estimates for 1977-1978." Journal of Econometrics 17 (2): 201-27.

Bresnahan, Timothy F., and Valerie A. Ramey. 1994. "Output Fluctuations at the Plant Level." Quarterly Journal of Economics 109 (3): 593-624.

-Bulow, Jeremy. 1986. “An Economic Theory of Planned Obsolescence.” Quarterly Journal of Economics 101 (4): 729-49.

Carlton, Dennis W., and Robert Gertner. 1989. "Market Power and Mergers in Durable-Good Industries." Journal of Law and Economics 32 (2): S203-26.

Carranza, Juan Esteban. 2007. "Estimation of Demand for Differentiated Durable Goods." Unpublished.

Chen, Jiawei, Susanna Esteban, and Matthew Shum. 2008. "Demand and Supply Estimation Biases Due to Omission of Durability." Journal of Econometrics 147 (2): 247-57.

Chen, Jiawei, Susanna Esteban, and Matthew Shum. 2010. "Do Sales Tax Credits Stimulate the Automobile Market?” International Journal of Industrial Organization 28 (4): 397-402.

Chen, Jiawei, Susanna Esteban, and Matthew Shum. 2013. "When Do Secondary Markets Harm Firms?: Dataset." American Economic Review. http://dx.doi.org/10.1257aer.103.7.2911.

Chevalier, Judith, and Austan Goolsbee. 2009. "Are Durable Goods Consumers Forward-Looking? Evidence from College Textbooks." Quarterly Journal of Economics 124 (4): 1853-84.

-Coase, Ronald H. 1972. "Durability and Monopoly." Journal of Law and Economics 15 (1): 143-49.

Copeland, Adam. 2006. "Intertemporal Substitution and Automobiles." Unpublished.

Copeland, Adam, Wendy Dunn, and George Hall. 2005. "Prices, Production and Inventories over the Automotive Model Year.” National Bureau of Economic Research Working Paper 11257.

Eberly, Janice C. 1994. “Adjustment of Consumers' Durables Stocks: Evidence from Automobile Purchases." Journal of Political Economy 102 (3): 403-36.

Erdem, Tulin, Susumu Imai, and Michael P. Keane. 2003. "Brand and Quantity Choice Dynamics under Price Uncertainty." Quantitative Marketing and Economics 1 (1): 5-64.

Esteban, Susanna. 2002. "Equilibrium Dynamics in Semi-Durable Goods Markets." Unpublished.

Esteban, Susanna, and Matthew Shum. 2007. "Durable-Goods Oligopoly with Secondary Markets: The Case of Automobiles." RAND Journal of Economics 38 (2): 332-54.

Government Accountability Office. 2005. "College Textbooks: Enhanced Offerings Appear to Drive Recent Price Increases.” Report to Congressional Requesters. GAO-05-806.

Gavazza, Alessandro, Alessandro Lizzeri, and Nikita Roketskiy. 2012. "A Quantitative Analysis of the Used Car Market." Unpublished.

Goettler, Ronald L., and Brett R. Gordon. 2009. “Does AMD Spur Intel to Innovate More?” Unpublished.

-Goldberg, Pinelopi Koujianou. 1995. "Product Differentiation and Oligopoly in International Markets: The Case of the U.S. Automobile Industry." Econometrica 63 (4): 891-951.

Gordon, Brett R. 2009. "A Dynamic Model of Consumer Replacement Cycles in the PC Processor Industry." Marketing Science 28 (5): 846-67.

Gowrisankaran, Gautam, and Marc Rysman. 2006. "Dynamics of Consumer Demand for New Durable Goods." Unpublished.

-Gul, Faruk. 1987. "Noncooperative Collusion in Durable Goods Oligopoly." RAND Journal of Economics $18(2): 248-54$.

-Hartmann, Wesley R. 2006. "Intertemporal Effects of Consumption and Their Implications for Demand Elasticity Estimates." Quantitative Marketing and Economics 4 (4): 325-49.

-Hendel, Igal, and Alessandro Lizzeri. 1999a. "Adverse Selection in Durable Goods Markets." American Economic Review 89 (5): 1097-115.

Hendel, Igal, and Alessandro Lizzeri. 1999b. "Interfering with Secondary Markets." RAND Journal of Economics 30 (1): 1-21.

Hendel, Igal, and Aviv Nevo. 2006. "Measuring the Implications of Sales and Consumer Inventory Behavior.” Econometrica 74 (6): 1637-73. 
- Iizuka, Toshiaki. 2007. "An Empirical Analysis of Planned Obsolescence." Journal of Economics and Management Strategy 16 (1): 191-226.

Johnson, Justin P. 2010. "Secondary Markets with Changing Preferences." Unpublished.

Liang, Meng-Yu. 1999. "Does a Second-Hand Market Limit a Durable Goods Monopolist's Market Power?" Unpublished.

Luo, Zhi-Quan, Jong-Shi Pang, and Daniel Ralph. 1996. Mathematical Programs with Equilibrium Constraints. New York: Cambridge University Press.

Melnikov, Oleg. 2000. "Demand for Differentiated Durable Products: The Case of the U.S. Computer Printer Market." Unpublished.

- Miller, Robert A. 1984. "Job Matching and Occupational Choice." Journal of Political Economy 92 (6): 1086-120.

Nair, Harikesh. 2007. "Intertemporal Price Discrimination with Forward-Looking Consumers: Application to the US Market for Console Video-Games." Quantitative Marketing and Economics 5 (3): 239-92.

Nissanoff, Daniel. 2006. Future Shop: How the New Auction Culture will Revolutionize the Way we Buy, Sell, and Get the Things we Really Want. New York: Penguin Press.

-Petrin, Amil. 2002. "Quantifying the Benefits of New Products: The Case of the Minivan." Journal of Political Economy 110 (4): 705-29.

Porter, Robert H., and Peter Sattler. 1999. "Patterns of Trade in the Market for Used Durables: Theory and Evidence." National Bureau of Economic Research Working Paper 7149.

- Rust, John. 1985. "Stationary Equilibrium in a Market for Durable Assets." Econometrica 53 (4): $783-805$.

- Rust, John. 1986. "When Is It Optimal to Kill Off the Market for Used Durable Goods?" Econometrica 54 (1): 65-86.

-Rust, John. 1987. "Optimal Replacement of GMC Bus Engines: An Empirical Model of Harold Zurcher." Econometrica 55 (5): 999-1033.

Schiraldi, Pasquale. 2006. "Automobile Replacement: A Dynamic Structural Approach.” Unpublished.

-Stolyarov, Dmitriy. 2002. "Turnover of Used Durables in a Stationary Equilibrium: Are Older Goods Traded More?" Journal of Political Economy 110 (6): 1390-413.

Su, Che-Lin, and Kenneth L. Judd. 2008. "Constrained Optimization Approaches to Estimation of Structural Models." Unpublished.

-Suslow, Valerie Y. 1986. "Estimating Monopoly Behavior with Competitive Recycling: An Application to Alcoa." RAND Journal of Economics 17 (3): 389-403.

-Swan, Peter L. 1972. "Optimum Durability, Second-Hand Markets, and Planned Obsolescence." Journal of Political Economy 80 (3): 575-85.

US Department of Labor, Bureau of Labor Statistics. 1994-2003. "Consumer Expenditure Survey: Interview Survey and Detailed Expenditure Files." Inter-university Consortium for Political and Social Research, Ann Arbor, MI [distributor]. ICPSR 06710, 02264, 02794, 02838, 02971, 03228, 03396, 03674, 03949, and 04184 (accessed January 18, 2008).

US Securities and Exchange Commission. 1994-2003. Annual Reports (Form 10-K) of Ford, General Motors, and Chrysler. http://www.sec.gov/cgi-bin/browse-edgar (accessed July 18, 2010).

-Waldman, Michael. 1993. “A New Perspective on Planned Obsolescence.” Quarterly Journal of Economics 108 (1): 273-83.

-Waldman, Michael. 1996. "Durable Goods Pricing When Quality Matters." Journal of Business 69 (4): 489-510. 